\title{
Cationic Oligomerization of Chlorostyrenes and $p$-Methoxystyrene: Selective Dimerization of Styrene Derivatives by Oxo Acids
}

\author{
Misao Hiza, Hiroshi Hasegawa, and Toshinobu Higashimura \\ Department of Polymer Chemistry, Kyoto University, \\ Yoshida, Sakyo-ku, Kyoto 606, Japan.
}

(Received January 22, 1980)

\begin{abstract}
In nonpolar solvents at a high temperature $\left(70^{\circ} \mathrm{C}\right)$, oxo acids or their derivatives $\left(\mathrm{AcClO}_{4}, \mathrm{CF}_{3} \mathrm{SO}_{3} \mathrm{H}\right.$, etc.) were found to be efficient and selective catalysts for the synthesis of linear unsaturated dimers from $o-, m$, and $p$-chlorostyrenes and $p$-methoxystyrene. Even $p$ methoxystyrene, having a strongly electron-donating methoxy group, was converted to a linear dimer in high yield ( $c a .80 \mathrm{wt} \%$ ). Selective linear dimerizations were also possible in a polar solvent in the presence of a common-ion salt, but in the absence of such a salt, the amount of higher oligomers increased in the products. Metal-halide catalysts $\left(\mathrm{BF}_{3} \mathrm{OEt}_{2}, \mathrm{SnCl}_{4}\right.$, and $\left.\mathrm{EtAlCl}_{2}\right)$ gave cyclic dimers and higher oligomers as well as linear dimers under similar conditions. These results suggest that the non-dissociated species in which the carbocation interacts strongly with the counterion plays an important role in the formation of linear dimers.

KEY WORDS Cationic Oligomerization / Selective Dimerization / Chlorostyrenes / p-Methoxystyrene / Oxo Acid / Metal Halide / Linear Unsaturated Dimer / Common-Ion Salt Effect / Propagating Species /
\end{abstract}

The cationic oligomerization of vinyl compounds at higher temperature is a useful reaction for producing oligomers because of the frequent transfer reactions brought on by unstable propagating carbocations. ${ }^{1}$ We have recently found that the molecular-weight distribution (MWD) of oligostyrenes could be controlled by the proper choice of catalysts, solvents, and reaction temperature; the linear dimer, ${ }^{2}$ trimers, ${ }^{3}$ or tetramers ${ }^{3}$ of styrene were formed in high yield under suitable conditions. Similarly, despite the presence of an electrondonating methyl group, methylstyrenes in conjunction with oxo acids or their derivatives gave linear dimers in high yield, whereas higher oligomers were formed by metal-halide catalysts. ${ }^{4}$ This difference was accounted for in terms of the interaction between the growing carbocation and the counterion derived from a catalyst. ${ }^{3,4}$

The facile linear dimerization of methylstyrenes ${ }^{4}$ has prompted us to explore further the effects of substituents on cationic oligomerizations. We therefore tried to dimerize two extreme monomers, chlorostyrenes and $p$-methoxystyrene, the former having an electron-withdrawing group and the latter with a strongly electron-donating $p$-substituent. Although the cationic polymerization of chlorostyrenes and $p$-methoxystyrene has been investigated extensively, ${ }^{1}$ there is a scarcity of information concerning their oligomerizations. Only the dimerization of $p$-methoxystyrene by sulfuric acid in 1,4dioxane has been reported ${ }^{5}$ and a general method is not known for the selective synthesis of the linear dimer of styrene derivatives.

Secondly, the present paper makes a comparison of oxo acids, including their derivatives, and metal halides as oligomerization catalysts, as was done in our previous work with styrene ${ }^{3}$ and methylstyrenes. ${ }^{4}$ These fundamental studies led to a new method for preparing linear unsaturated dimers of styrene derivatives.

\section{EXPERIMENTAL}

\section{Materials}

$p$-Chlorostyrene ( $p$-ClSt) and $p$-methoxystyrene ( $p$-MeOSt) were obtained as previously reported. ${ }^{6}$ 
$o$-Chlorostyrene $(o$-ClSt) and $m$-chlorostyrene $(m$ ClSt) were both commercially supplied. These monomers (purity $>99 \%$; by gas chromatography) were distilled twice over $\mathrm{CaH}_{2}$ under reduced pressure just before use. Solvents [benzene $\left(\mathrm{C}_{6} \mathrm{H}_{6}\right)$, tetrachloromethane $\left(\mathrm{CCl}_{4}\right)$, and 1,2-dichloroethane $\left.\left[\left(\mathrm{CH}_{2} \mathrm{Cl}\right)_{2}\right]\right]$ were purified as reported. ${ }^{3}$ Acetyl perchlorate $\left(\mathrm{AcClO}_{4}\right)^{7}$ and $\left(n-\mathrm{C}_{4} \mathrm{H}_{9}\right)_{4} \mathrm{~N}^{+} \mathrm{SO}_{3} \mathrm{CF}_{3}^{-8}$ were synthesized as described elsewhere. Commercial $\mathrm{BF}_{3} \mathrm{OEt}_{2}, \mathrm{SnCl}_{4}, \mathrm{EtAlCl}_{2}, \mathrm{CH}_{3} \mathrm{SO}_{3} \mathrm{H}$, and $\mathrm{C}_{6} \mathrm{H}_{5} \mathrm{Br}$ were used after distillation under reduced or atmospheric pressure. $\mathrm{CF}_{3} \mathrm{SO}_{3} \mathrm{H}, \mathrm{I}_{2}$, and $\left(n-\mathrm{C}_{4} \mathrm{H}_{9}\right)_{4} \mathrm{~N}^{+} \mathrm{ClO}_{4}{ }^{-}$(all guaranteed reagents) were used without further purification.

\section{Procedures}

The reaction was carried out under a dry nitrogen atmosphere. ${ }^{3}$ In this procedure, the concentration of water in the reaction mixture was smaller than $0.5 \mathrm{mM}$ by the Fischer method. The reaction rate as well as the MWD and structure of product was reproducible as long as the water concentration was kept constant.

Determination of the MWD of oligomers and separation of dimers were performed by liquid chromatography (HLC) in chloroform. ${ }^{4}$ The analytic $(7.2 \mathrm{~mm}$ i.d. $\times 500 \mathrm{~mm})$ and preparative columns $(21.5 \mathrm{~mm}$ i.d. $\times 500 \mathrm{~mm})$ were packed with a JSP-101 polystyrene gel $(20,000 \mathrm{TP} / 500 \mathrm{~mm}$; exclusion limit $<3,000)$. The weight fraction of each oligomer was calculated from the HLC peak area recorded on a refractive index detector, since, for oligostyrenes obtained by acidic catalysts, the dependence of HLC detector response on their degree of polymerization is considerably great in the spectroscopic (ultraviolet) detection (e.g., at $254 \mathrm{~nm}$ ) but is small in the differentialrefractometric detection as reported for oligostyrenes prepared by anionic polymerization. ${ }^{9}$ The MWD of higher oligomers was measured by gelpermeation chromatography (GPC) on a Shimadzu GPC-700 chromatograph equipped with polystyrene gel columns SG-1, 2, 3, 4, and 5 (TP/ft: 1650, $1040,2103,1920$, and 1190, respectively; exclusion limit $\left.<10^{6}\right)$. ${ }^{1} \mathrm{H}$ NMR spectra $(100 \mathrm{MHz})$ were recorded on a Varian HA-100 spectrometer at room temperature in $\mathrm{CCl}_{4}$.

\section{RESULTS}

\section{Oligomerization of Chlorostyrenes}

$M W D$ of the Products. Figure 1 shows the effects of solvents on the MWD of $o-, m-$, and $p$-ClSt oligomers obtained with $\mathrm{AcClO}_{4}$ at $70^{\circ} \mathrm{C}$. Under these conditions, dimer content was highest among low-molecular-weight oligomers. Especially in a nonpolar solvent, $\mathrm{CCl}_{4}$, dimers were formed in high yield $(\mathrm{ca} .80 \mathrm{wt} \%)$ from each chlorostyrene. The dimer yield in a polar solvent, $\left(\mathrm{CH}_{2} \mathrm{Cl}\right)_{2}$, was smaller than in $\mathrm{CCl}_{4}$, and particularly $o$-ClSt and $p$-ClSt

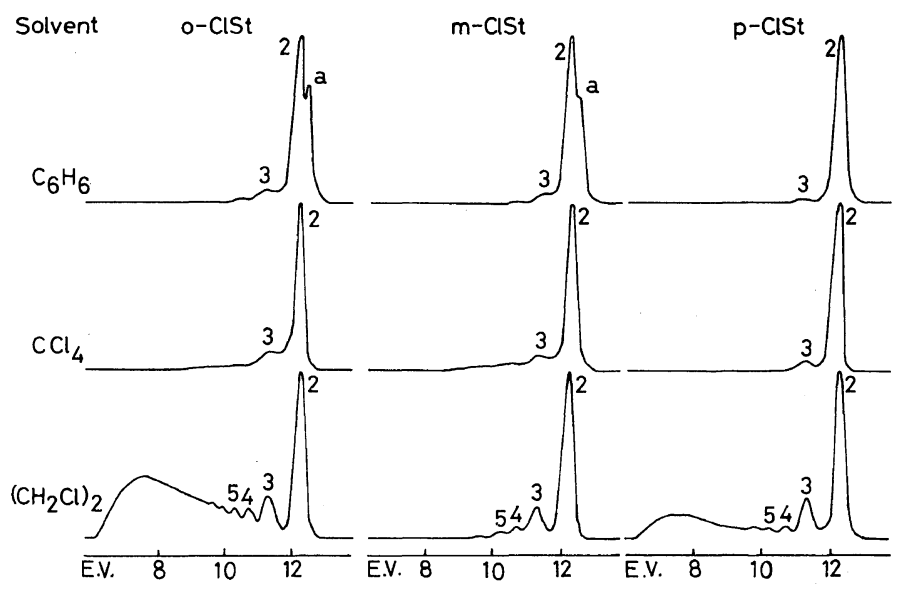

Figure 1. Effect of solvents on MWD in the oligomerization of chlorostyrenes by $\mathrm{AcClO}_{4}$ at $70^{\circ} \mathrm{C}$ : $[\mathrm{M}]_{0}=0.10 \mathrm{M} ;[\mathrm{C}]=0.50 \sim 4.0 \mathrm{mM}$; conversion $>65 \%$. The numbers indicate the degree of polymerization. Peak a refers to an alkylation product (3a).

E.V., elution volume. 


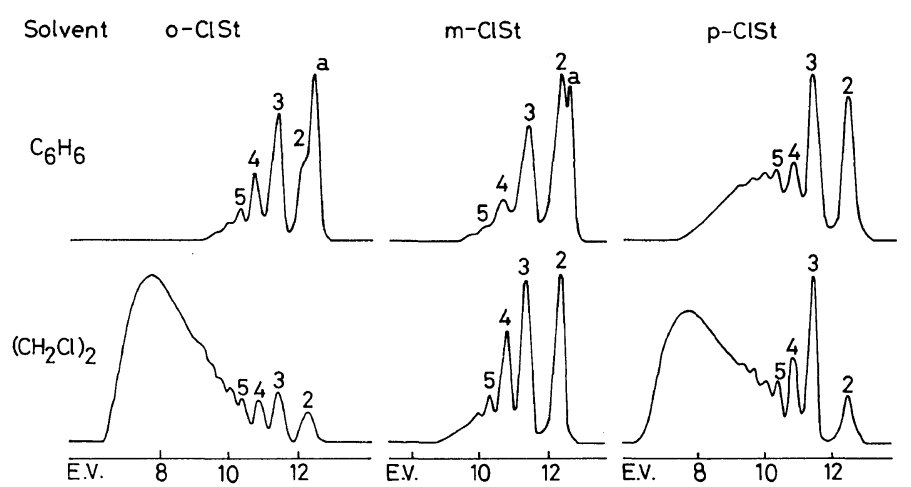

Figure 2. Effects of solvents on $\mathrm{MWD}$ in the oligomerization of chlorostyrenes by $\mathrm{BF}_{3} \mathrm{OEt}_{2}$ at $80^{\circ} \mathrm{C}$ : $[\mathrm{M}]_{0}=0.10 \mathrm{M} ;[\mathrm{C}]=10.0 \sim 20.0 \mathrm{mM}$; conversion $>65 \%$ [except for $o-\mathrm{ClSt}$ in $\mathrm{C}_{6} \mathrm{H}_{6}(5 \%)$ and $m-\mathrm{ClSt}_{\text {in }} \mathrm{C}_{6} \mathrm{H}_{6}$ $(24 \%)$. The numbers indicate the degree of polymerization. Peak a refers to an alkylated product (3a).

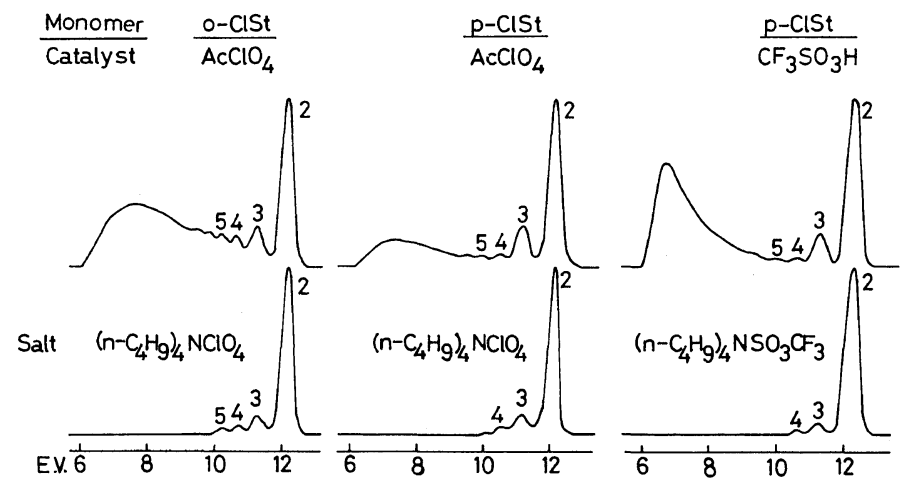

Figure 3. Effect of common-ion salts on MWD in the ClSt oligomerization in $\left(\mathrm{CH}_{2} \mathrm{Cl}\right)_{2}$ at $70^{\circ} \mathrm{C}$ : $[\mathrm{M}]_{0}=0.10 \mathrm{M} .[\mathrm{C}]_{0}: \mathrm{AcClO}_{4}, 0.50 \mathrm{mM} ; \mathrm{CF}_{3} \mathrm{SO}_{3} \mathrm{H}, 0.30 \mathrm{mM}$. [Salt]: $\left(n-\mathrm{C}_{4} \mathrm{H}_{9}\right)_{4} \mathrm{~N}^{+} \mathrm{ClO}_{4}{ }^{-}, 0.50 \mathrm{mM} ;(n-$ $\left.\mathrm{C}_{4} \mathrm{H}_{9}\right)_{4} \mathrm{~N}^{+} \mathrm{SO}_{3} \mathrm{CF}_{3}{ }^{-}, 0.30 \mathrm{mM}$; conversion $>65 \%$. The numbers indicate the degree of polymerization.

produced large amounts of higher oligomers as well as dimers. In the aromatic solvent, $\mathrm{C}_{6} \mathrm{H}_{6}, o$-ClSt or $m$-ClSt resulted in an alkylation product between the monomer and the solvent (peak a in Figure 1; vide infra), although the dimer yield was high.

Figure 2 shows the effects of solvents on the MWD of $o-, m-$, and $p$-ClSt oligomers formed by $\mathrm{BF}_{3} \mathrm{OEt}_{2}$ at $80^{\circ} \mathrm{C}$. The average-molecular weight of these oligomers was always higher than that of the corresponding products obtained by $\mathrm{AcClO}_{4}$. Polymers were produced from $o$ - and $p$-ClSt in $\left(\mathrm{CH}_{2} \mathrm{Cl}\right)_{2}$, whereas $m$-ClSt mainly formed dimers and trimers in both polar and nonpolar solvents [e.g., $33 \mathrm{wt} \%$ dimers and $29 \mathrm{wt} \%$ trimers in $\left.\left(\mathrm{CH}_{2} \mathrm{Cl}\right)_{2}\right]$. The alkylation product of $o$-ClSt or $m$ ClSt (peak a in Figure 2) was formed in $\mathrm{C}_{6} \mathrm{H}_{6}$ and its content was higher than in the $\mathrm{AcClO}_{4}$-catalyzed reaction.

Common-Ion Salt Effect. The large effect of solvent polarity on the MWD of products suggests a change in the nature of the reaction intermediate with solvents. Common-ion salt effects were thus investigated in the $\mathrm{ClSt}$ oligomerizations in $\left(\mathrm{CH}_{2} \mathrm{Cl}\right)_{2}$ where polymeric materials were obtained together with dimers.

A common-ion salt $\left[\left(n-\mathrm{C}_{4} \mathrm{H}_{9}\right)_{4} \mathrm{~N}^{+} \mathrm{ClO}_{4}{ }^{-}\right]$, equimolar to the catalyst, was added to the systems catalyzed by $\mathrm{AcClO}_{4}$ to suppress the dissociation of the growing species. ${ }^{8,10}$ Similar experiments were performed with $\left(n-\mathrm{C}_{4} \mathrm{H}_{9}\right)_{4} \mathrm{~N}^{+} \mathrm{SO}_{3} \mathrm{CF}_{3}{ }^{-}$on the $p$ $\mathrm{ClSt}-\mathrm{CF}_{3} \mathrm{SO}_{3} \mathrm{H}-\left(\mathrm{CH}_{2} \mathrm{Cl}\right)_{2}$ system and the products were similar to those formed by $\mathrm{AcClO}_{4} \cdot{ }^{3,4}$ The 
reaction rates definitely decreased with the addition of common-ion salts. Figure 3 shows the effects on the MWD of the product oligomers. The addition of these salts completely suppressed the formation of higher oligomers, resulting in a definite increase in dimer yield.

End-Group Structure. The dimer fraction (elution volume, $11.7-13.0 \mathrm{ml}$ ) of the products shown in Figures 1 and 2 was separated by preparative HLC to determine its structure by ${ }^{1} \mathrm{H}$ NMR. The dimer fraction was comprised of the following three compounds (1a, 2a, and 3a). Each content was

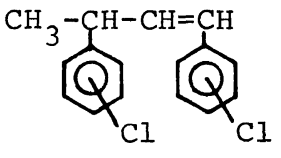

$1 \mathbf{a}$

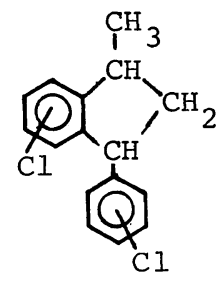

$\mathbf{2 a}$

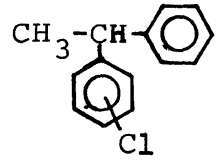

3a determined by ${ }^{1} \mathrm{H}$ NMR on the basis of the olefin protons for $1 \mathbf{a}^{4}$, the methine proton $\left(\mathrm{Ar}_{2} \mathrm{CH}\right)$ for $\mathbf{2} \mathbf{a}^{4}$, and the methyl protons for $\mathbf{3 a} .{ }^{11}$ Table I shows the composition of the dimer fraction. The com- position was influenced little by conversion unless the reaction was quenched after prolonged standing following its completion. The oligomerization of CISt was characterized to a lesser extent by cyclization (to 2a) and the promoted reaction with aromatic solvents (alkylation to 3a), when compared with those of styrene and methylstyrenes. ${ }^{4}$ The cyclic dimers (2a) were not produced by oxo acids. The $p$-ClSt dimer was only unsaturated, whereas the $o$-ClSt or $m$-ClSt dimers consisted of the unsaturated ones (1a) and the alkylation products (3a) owing to lower reactivity of $o$-ClSt or $m$-ClSt monomer than $p$-ClSt. On the other hand, besides the formation of the unsaturated dimer (1a) for $p$ $\mathrm{ClSt}, \mathrm{BF}_{3} \mathrm{OEt}_{2}$ promoted the formation of the alkylated product (3a) for $p$-ClSt, and this can be explained in terms of the weak interaction between the growing carbocation and the counterion. The cyclic dimer (2a) for $m$-ClSt was obtained in greater yield than that for $p$-ClSt by $\mathrm{BF}_{3} \mathrm{OEt}_{2}$ since cyclization was further facilitated by the increase in the electron density of the ortho positions due to the meta-chloro group.

\section{Oligomerization of p-Methoxystyrene}

The high reactivity of $p$-MeOSt allows us to employ a wide variety of catalysts to demonstrate the effect of counterions on dimerization. Figure 4 shows the MWD of $p$-MeOSt oligomers obtained under various conditions. Unexpectedly, the main product formed by oxo acids (A, B, E) and iodine (C) in $\mathrm{C}_{6} \mathrm{H}_{6}$ was a dimer. The dimer yields were over $50 \mathrm{wt} \%$, although they were smaller than those for

Table I. Composition of the dimer fraction in chlorostyrene oligomerizations ${ }^{a}$

\begin{tabular}{|c|c|c|c|c|}
\hline \multirow{2}{*}{ Catalyst } & \multirow{2}{*}{ Solvent } & \multicolumn{3}{|c|}{ 1a $\left(\mathrm{mol}^{\circ} \%\right)$} \\
\hline & & $o$-ClSt & $m$-ClSt & $p$-CISt \\
\hline $\mathrm{AcClO}_{4}$ & $\mathrm{CCl}_{4}$ & 100 & 100 & 100 \\
\hline $\mathrm{AcClO}_{4}$ & $\mathrm{C}_{6} \mathrm{H}_{6}$ & $50(50)^{\mathrm{b}}$ & $48(52)^{b}$ & $100(0)^{\mathrm{b}}$ \\
\hline $\mathrm{AcClO}_{4}$ & $\left(\mathrm{CH}_{2} \mathrm{Cl}\right)_{2}$ & 100 & 100 & 100 \\
\hline $\mathrm{AcClO}_{4}{ }^{\mathrm{c}}$ & $\left(\mathrm{CH}_{2} \mathrm{Cl}\right)_{2}$ & 100 & 100 & 100 \\
\hline $\mathrm{BF}_{3} \mathrm{OEt}_{2}$ & $\mathrm{C}_{6} \mathrm{H}_{6}$ & $-^{\mathrm{d}}$ & $32(53)^{\mathbf{b}, \mathbf{e}}$ & $72(28)^{b}$ \\
\hline $\mathrm{BF}_{3} \mathrm{OEt}_{2}$ & $\left(\mathrm{CH}_{2} \mathrm{Cl}\right)_{2}$ & $77^{e}$ & $42^{\mathrm{e}}$ & 100 \\
\hline
\end{tabular}

${ }^{a}$ Reaction conditions are the same as in Figures $1-3$.

b Parentheses indicate compositions of alkylation product.

c $\left(n-\mathrm{C}_{4} \mathrm{H}_{9}\right)_{4} \mathrm{~N}^{+} \mathrm{ClO}_{4}^{-}$, equimolar to the catalyst, was added.

${ }^{d}$ Not determined.

e The other was $\mathbf{2 a}$. 


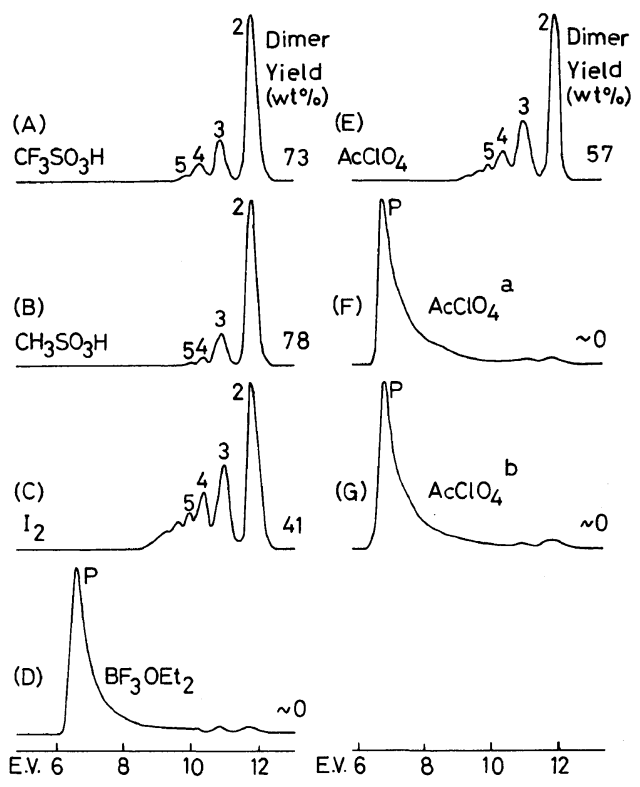

Figure 4. Effect of reaction conditions on MWD in the oligomerization of $p$-MeOSt in $\mathrm{C}_{6} \mathrm{H}_{6}$ at $70^{\circ} \mathrm{C}$ : $[\mathrm{M}]_{0}=0.10 \mathrm{M} ;[\mathrm{C}]_{0}(\mathrm{mM}):(\mathrm{A}), 0.02 ;(\mathrm{B}), 2.0 ;(\mathrm{C}), 10.0$; (D), $1.0 ;(\mathrm{E}), 0.01 ;(\mathrm{F}), 0.05 ;(\mathrm{G}), 0.005{ }^{\mathrm{a}}$ At $0^{\circ} \mathrm{C}^{\mathrm{b}}$ In $\left(\mathrm{CH}_{2} \mathrm{Cl}\right)_{2}$ solvent. Peak $\mathrm{p}$ refers to a high-molecularweight compound $\left(M W>10^{4}\right)$.

styrene, ${ }^{2,3}$ methylstyrenes, ${ }^{4}$ and $\mathrm{ClSt}$.

The dimer was identified as a linear unsaturated isomer [1,3-bis ( $p$-methoxyphenyl)but-1-ene] by ${ }^{1} \mathrm{H}$ NMR $\left[\delta 1.37\left(3 \mathrm{H}, \mathrm{d}, \mathrm{CH}_{3}, J=7 \mathrm{~Hz}\right), 3.47(1 \mathrm{H}, \mathrm{m}\right.$, $-\mathrm{CH}-), 3.64\left(6 \mathrm{H}, \mathrm{s}, \mathrm{CH}_{3} \mathrm{O}\right), 6.16(2 \mathrm{H}, \mathrm{m}$, $-\mathrm{CH}=\mathrm{CH}-)$, and $6.9 \mathrm{ppm}(8 \mathrm{H}, \mathrm{m}$, aromatic)]. The infrared spectrum of this dimer exhibited a strong absorption at $965 \mathrm{~cm}^{-1}$ attributable to the trans- double bond. Although it was reported that $p$ MeOSt was dimerized with $\mathrm{H}_{2} \mathrm{SO}_{4}$ in 1,4-dioxane, ${ }^{5}$ the yield of linear dimer was only $68 \mathrm{wt} \%$ under these conditions, accompanying higher oligomers $(10 \mathrm{wt} \%)$ and an unidentified product near the dimer peak.

The reactions catalyzed by an oxo acid $\left(\mathrm{AcClO}_{4}\right)$ at a low temperature $(\mathrm{F})$ or in $\left(\mathrm{CH}_{2} \mathrm{Cl}\right)_{2}(\mathrm{G})$, or by a metal halide (D) and others $\left(\mathrm{SnCl}_{4}\right.$ and $\left.\mathrm{EtAlCl}_{2}\right)$ in $\mathrm{C}_{6} \mathrm{H}_{6}$ gave higher oligomers (molecular weight, $10,000-30,000)$ with trace amounts of the dimer even at a low $[\mathrm{M}]_{0}(0.10 \mathrm{M})$.

\section{DISCUSSION}

\section{Selective Dimerization by Oxo Acids}

Table II summarizes dimer yields in the oligomerization of a series of styrene derivatives by $\mathrm{AcClO}_{4}$ at $70^{\circ} \mathrm{C}$. Irrespective of the nature of substituents, linear unsaturated dimers 1 were produced in good yield in nonpolar solvent. No isomers were formed

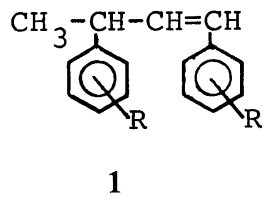

$$
\begin{aligned}
\mathrm{R}= & \mathrm{Cl} \\
& \mathrm{H} \\
& \mathrm{Me} \\
& p-\mathrm{OMe}
\end{aligned}
$$

under these conditions ( $c f$. Table III). The other oxo acids $\left(\mathrm{CF}_{3} \mathrm{SO}_{3} \mathrm{H}, p-\mathrm{CH}_{3} \mathrm{C}_{6} \mathrm{H}_{4} \mathrm{SO}_{3} \mathrm{H}\right.$, etc.) similarly produced the dimers (1) in high yield.

It is particularly interesting that the linear dimer (1d) was obtained in good yield from $p$-MeOSt which has a strong electron-donating methoxy

\begin{tabular}{|c|c|c|c|c|c|c|}
\hline \multirow{2}{*}{ Substituent } & \multicolumn{3}{|c|}{$\mathrm{C}_{6} \mathrm{H}_{6}$ solvent } & \multicolumn{3}{|c|}{$\left(\mathrm{CH}_{2} \mathrm{Cl}\right)_{2}$ solvent } \\
\hline & ortho & meta & para & ortho & meta & para \\
\hline $\mathrm{OMe}$ & $-^{a}$ & $-^{a}$ & $56.4(78.0)^{\mathrm{b}}$ & $-^{\mathrm{a}}$ & $-^{a}$ & $\sim 0$ \\
\hline $\mathrm{Me}$ & 97.4 & 87.4 & 85.4 & 47.3 & 36.9 & 18.5 \\
\hline $\mathrm{H}$ & 88.3 & 88.3 & 88.3 & 50.0 & 50.0 & 50.0 \\
\hline $\mathrm{Cl}$ & $77.1^{\mathrm{c}}$ & $82.2^{\mathrm{c}}$ & $88.5^{\mathrm{c}}$ & 21.6 & 74.9 & 43.6 \\
\hline
\end{tabular}
group and is readily polymerized to higher molec-

Table II. Dimer contents ( $\mathrm{wt} \%$ ) of oligomers formed by $\mathrm{AcClO}_{4}$ at $70^{\circ} \mathrm{C}\left([\mathrm{M}]_{0}=0.10 \mathrm{M}\right)$

${ }^{\text {a }}$ Not determined.

b Catalyzed by $\mathrm{CH}_{3} \mathrm{SO}_{3} \mathrm{H}$.

c In $\mathrm{CCl}_{4}$ solvent. 
ular weight compounds. The good dimer yields for oxo acids and iodine (Figure 4), together with the polymer formation by metal halides, indicate the importance of strong nucleophilicity of counterions in the dimerization. A higher temperature, which promotes proton elimination, was also profitable to produce the dimer. The effect of solvent polarity on the MWD showed that the non-dissociated species is required for selective dimerization of styrene derivatives, as will be discussed later.

The selective linear dimerization catalyzed by oxo acids in nonpolar solvents indicates a promoted $\beta$ hydrogen transfer from the growing end, which should be induced by the strong interaction of the oxygen atoms in the counterion that associates close to the cationic site. ${ }^{2}$

Dimer yields were decreased by increasing solvent polarity or by the use of metal halides, and this could be done because of the resulting weakened interaction between the growing carbocation and the counterion. ${ }^{3,4}$ Thus, the dimerization with oxo acid catalysts in nonpolar solvents is a generally applicable, selective process for preparing the linear unsaturated dimers (1) of styrene derivatives.

\section{Effect of Catalysts and Substituents on Dimer Structure}

The structures of dimers cationically obtained from various styrene derivatives are summarized in Table III. "Linear," "cyclic," and "alkylated" indicate the compounds (1), (2), and (3), respectively. On the whole, $\mathrm{AcClO}_{4}$ catalyst produced the linear unsaturated structure (1) predominantly,<smiles>[R]c1cccc(C2CC(C)c3ccccc32)c1[R]</smiles>

2

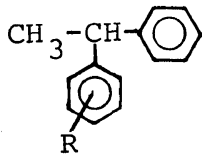

3

$$
(\mathrm{R}=\mathrm{Cl}(\mathbf{2 a}, \mathbf{3 a}), \mathrm{H}, \mathrm{Me}, \mathrm{OMe})
$$

while $\mathrm{BF}_{3} \mathrm{OEt}_{2}$ catalyst promoted the formation of the cyclic dimers 2 . These catalytic differences can be explained on the basis of the difference in the nature of counterions discussed above.

The linear dimers 1 were formed in high yield irrespective of the nature of substituents in nonpolar solvents ( $c f$. Table II). On the other hand, in a polar solvent, electron-donating substituents enhanced the formation of the cyclic dimers $\mathbf{2}$ and/or higher oligomers because of the increased electron density of the penultimate phenyl group in the cation and the weakened interaction between the growing end and its counterion.

\section{Salt Effect and the Nature of the Intermediate}

In the oligomerization of $o$-ClSt and $p$-ClSt with oxo acid catalysts in a polar solvent, higher oligomers were entirely suppressed by the addition of common-ion salts which depress the dissociation of the growing carbocation, yielding the linear dimers selectively (Figure 3 ). Therefore, the selective dimerization is attributed to a "non-dissociated" propagating species. ${ }^{8,10}$ The intermediate, respon-

Table III. Dimer structures of styrene derivatives $\left([\mathrm{M}]_{0}=0.10 \mathrm{M}\right)$

\begin{tabular}{lcll}
\hline \multirow{2}{*}{$\begin{array}{c}\text { Catalyst } \\
(\text { Temp })\end{array}$} & $\begin{array}{c}\text { Ring } \\
\text { substituents }\end{array}$ & \multicolumn{1}{c}{ Solvent } \\
\cline { 3 - 4 } & & \multicolumn{1}{c}{ Nonpolar } & \multicolumn{1}{c}{ Polar } \\
\hline & -MeO & Linear & - $^{\mathrm{c}}$ \\
$\mathrm{AcClO}_{4}$ & $\mathrm{Me}$ & Linear & Linear, cyclic \\
$\left(70^{\circ} \mathrm{C}\right)$ & $\mathrm{H}$ & Linear & Linear \\
& $\mathrm{Cl}$ & Linear, alkylated & Linear \\
\hline & $\mathrm{Me}$ & Linear, cyclic & (Linear), ${ }^{\mathrm{b}}$ cyclic \\
$\mathrm{BF}_{3} \mathrm{OEt}_{2}$ & $\mathrm{H}$ & Linear, (cyclic) & c $^{\mathrm{b}}$ \\
$\left(80^{\circ} \mathrm{C}\right)$ & $\mathrm{Cl}$ & Linear, (cyclic), ${ }^{\mathrm{b}}$ alkylated & Linear, cyclic \\
\hline
\end{tabular}

a Only in aromatic solvent $\left(\mathrm{C}_{6} \mathrm{H}_{6}\right)$.

b Parentheses indicate a minor content.

c Not determined. 
sible for the higher oligomers formed in the absence of added salts, should be a "dissociated" species that is resonance-stabilized by the chlorine atom.

In spite of extensive studies on the salt effects on cationic polymerization, ${ }^{8.10}$ no previous papers, to our knowledge, deal with the effect of common-ions on cationic oligomerization at high temperatures. This is the first work to disclose that oligomerization by oxo-acid catalysts involves two propagating species, the presence of which has been established by us in the corresponding polymerization. ${ }^{8,10}$

As a synthetic method for the linear dimers 1, oligomerization in polar solvents in the presence of a common-ion salt is more advantageous than that in nonpolar media because of its shorter reaction time, high selectivity ( $78-88 \mathrm{wt} \%$ ), and the absence of the by-product 3 by alkylation.

\section{REFERENCES}

1. For reviews, see (a) P. H. Plesch, Ed., "The Chemistry of Cationic Polymerization," Pergamon
Press, New York, N.Y., 1963; (b) J. P. Kennedy, "Cationic Polymerization of Olefins: A Critical Inventory," Wiley-Interscience, New York, N.Y., 1975.

2. T. Higashimura and H. Nishii, J. Polym. Sci., Polym. Chem. Ed., 15, 329 (1977).

3. T. Higashimura, M. Hiza, and H. Hasegawa, Macromolecules, 12, 217 (1979).

4. T. Higashimura, M. Hiza, and H. Hasegawa, Macromolecules, 12, 1058 (1979).

5. R. Corriu, J. Guenzet, and C. Reye, C. R. Acad. Sci., Ser. C, 270, 566 (1970).

6. (a) R. F. Nystrom and W. G. Brown, J. Am. Chem. Soc., 69, 1197 (1947); (b) C. S. Marvel and G. L. Schertz, ibid., 65, 2054 (1943).

7. T. Masuda and T. Higashimura, J. Macromol. Sci., Chem., A5, 547 (1971).

8. M. Sawamoto, T. Masuda, and T. Higashimura, Makromol. Chem., 177, 2995 (1976).

9. M. Fukuda, T. Takamatsu, K. Tago, T. Okada, and T. Sato, Kobunshi Ronbunshu, 36, 7 (1979).

10. T. Higashimura and O. Kishiro, J. Polym. Sci., Polym. Chem. Ed., 12, 967 (1974).

11. H. Hasegawa and T. Higashimura, Polym. J., 11, 737 (1979). 